\title{
Effects of L-NG-Monomethyl-Arginine on Apoptosis of Articular Chondrocytes
}

\author{
GUODONG WANG AND BIN HE* \\ Department of Orthopedics, The Second Affiliated Hospital of Nanjing Medical University, No. 121 Jiangjiayuan, Nanjing \\ 210011, Jiangsu Province, P. R. China
}

Wang et al.: Effects of L-NG-Monomethyl-Arginine

\begin{abstract}
We aimed to investigate the effects of L-NG-monomethyl-arginine on the apoptosis of articular chondrocytes. 30 rabbits were randomly divided into six groups $(n=5)$. The pathological changes were detected by Hematoxylin and Eosin staining. The expression levels of synovial fluid and serum nitric oxide were measured. The apoptosis of chondrocytes was tested using the terminal deoxynucleotidyl transferase dUTP nick end labeling assay. The expression levels of reconstituted B-cell lymphoma-2 and human B-cell lymphoma-2 associated $X$ protein in cartilage tissues were detected by immunohistochemical assay. The Mankin score of the model group was significantly higher than that of the control group $(p<0.01)$. The scores significantly decreased in L-NG-monomethyl-arginine treatment groups $(p<0.05)$. The expression levels of B-cell lymphoma-2 associated $X$ protein, apoptosis rate and index of chondrocytes, and those of synovial fluid and serum nitric oxide were markedly higher in the model group than those in the control group $(\mathbf{p}<\mathbf{0 . 0 1})$. However, the expression levels of B-cell lymphoma-2 in model and control groups were similar ( $p>0.05)$. With increasing L-NG-monomethyl-arginine treatment dose, the expression level of B-cell lymphoma-2 and B-cell lymphoma-2/B-cell lymphoma-2 associated $X$ protein ratio were significantly elevated $(p<0.05)$. L-NG-monomethyl-arginine reduced the expressions of synovial fluid and serum nitric oxide, and raised B-cell lymphoma-2/B-cell lymphoma-2 associated $X$ protein ratio, thereby inhibiting chondrocyte apoptosis.
\end{abstract}

Key words: L-NG-monomethyl-arginine, knee joint osteoarthritis, articular cartilage, apoptosis

At present, the Chinese population is aging. Epidemiological investigations indicate that the incidence rate of degenerative osteoarthritis (OA) is increasing annually. It is expected that, in the near future, the disease will be one of the main causes of disability among adult males in China ${ }^{[1,2]}$. The main pathological characteristics of degenerative OA include significant apoptosis of cartilage cells in joints and progressive degradation of the matrices outside articular chondrocytes ${ }^{[3]}$. The expression levels of nitric oxide (NO) and its byproducts are significantly positively correlated with the number of apoptotic cells in articular cartilage and the severity of OA. In the early stage of the disease, $\mathrm{NO}$ and its byproducts stimulate and induce the apoptosis of articular cartilage cells, leading to the pathological degradation of articular cartilage $^{[4,5]}$. L-NG-monomethyl-arginine (L-NMMA), as a congener of L-arginine, competes with it at the binding sites of nitric oxide synthase (NOS). L-NMMA can inhibit three NOS's with low selectivity, resulting

*Address for correspondence E-mail: hebinsahnmu@hotmail.com in the irreversible inactivation of inducible nitric oxide synthase (iNOS) with extended time ${ }^{[6]}$. Thereby motivated, we herein evaluated the influence of L-NMMA on the apoptosis of articular chondrocytes in OA rabbits.

\section{MATERIALS AND METHODS}

\section{Materials:}

L-NMMA was purchased from Sigma (USA). S-P kit was bought from Wuhan Boster Biological Technology Co., Ltd. (China). 3,3'-Diaminobenzidine was bought from Fuzhou Maixin Biotechnology Development Co.,

\footnotetext{
This is an open access article distributed under the terms of the Creative Commons Attribution-NonCommercial-ShareAlike 3.0 License, which allows others to remix, tweak, and build upon the work non-commercially, as long as the author is credited and the new creations are licensed under the identical terms
}

Accepted 26 February 2021

Revised 05 December 2020

Received 19 June 2020

Indian J Pharm Sci 2021;83(1):134-139 
Ltd. (China). Terminal deoxynucleotidyl transferase dUTP nick end labeling (TUNEL) assay kit was purchased from Nanjing KeyGen Biotech Co., Ltd. (China). NO detection kit was obtained from Nanjing Jiancheng Bioengineering Institute (China). Annexin A V-FITC apoptosis kit was obtained from Gibco (USA). Human Bone Morphogenetic Protein 2 (BMP2) and Transforming growth factor beta 1 (TGF $\beta 1$ ) serum ELISA kits, as well as caspases-3, B-cell lymphoma-2 associated $\mathrm{X}$ protein (Bax) and B-cell lymphoma-2 (Bcl-2) mouse anti-rabbit antibodies, were purchased from Beijing Zhongshan Technology Co., Ltd. (China).

\section{Animal grouping and model establishment:}

All animal experiments have been approved by the ethics committee of our hospital, and great efforts have been made to minimize their suffering. The experimental animals were provided by the Experimental Animal Center of Xuzhou Medical College. Thirty female or male Sun Protection Factor (SPF) grade New Zealand white rabbits aged about 8 mo and weighing $2.0 \sim 2.5 \mathrm{~kg}$ were selected. The 30 rabbits were randomly divided into 5 groups $(n=6)$ : normal group (Group A) without treatment; OA model group (Group B) established by the plaster immobilization method (fig. 1); low-dose L-NMMA treatment group (Group C), medium-dose L-NMMA treatment group (Group D) and high-dose L-NMMA treatment group (Group E): The articular cavities of OA model animals were injected with $0.5 \mathrm{ml}$ of L-NMMA at $0.1 \%, 0.25 \%$ and $0.5 \%$, respectively, 7 times every $3 \mathrm{~d}$. After each injection, infusion and withdrawal were repeated twice to ensure successful intra-articular injection.

\section{Sampling of joint fluid and serum:}

Arthrocentesis was performed on the right knee joint of each group. After the needle penetrated the joint cavity, $1 \mathrm{ml}$ of $0.9 \%$ normal saline solution was injected slowly

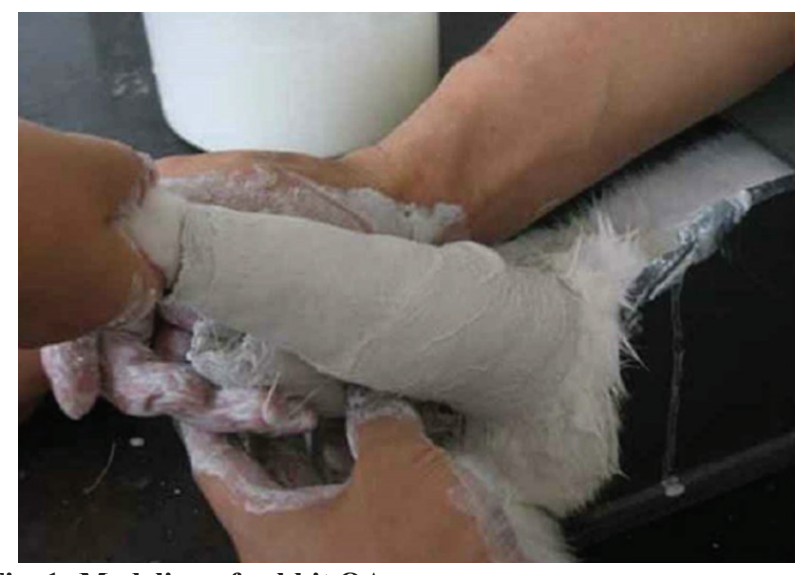

Fig. 1: Modeling of rabbit OA

January-February 2021

Indian Journal of Pharmaceutical Sciences

Under anesthesia, the rabbits were killed by head knocking with a hard object. Immediately after their death, the right knee joint cavity was cut open to observe the lesions in articular cartilage, synovium and other parts with naked eye. Then cartilage tissues in the tibial plateau and the lower edge of femoral condyle were resected with a blade, fixed, dehydrated, transparentized, embedded into paraffin, sectioned, and subjected to Hematoxylin and Eosin (HE) staining and TUNEL assay. The lesions were graded according to the modified Mankin histologic/histochemical grading system $^{[7,8]}$. Bax and Bcl-2 expressions in cartilage tissues were detected by immunohistochemical assay,

Then the cavity liquid was collected and centrifuged at $1,000 \mathrm{r} / \mathrm{min}$ for $5 \mathrm{~min}$, and finally the supernatant was collected and stored at $-20^{\circ}$. Subsequently, $6 \mathrm{ml}$ of blood was drawn from the ear vein and centrifuged at $3500 \mathrm{r} /$ min for $10 \mathrm{~min}$, and then the upper layer serum was collected and kept in a refrigerator prior to detection.

\section{Detection of synovial fluid and serum NO:}

The nitrate reductase method was used to detect NO expression levels in synovial fluid and serum. A standard curve was plotted by the following procedure. prepare $0-2.0 \mu \mathrm{g}$ of standard nitrite nitrogen solutions. After being shaken well, the solutions were incubated in a $30^{\circ}$ incubator or thermostatic water bath for $30 \mathrm{~min}$, and then measured at $540 \mathrm{~nm}$. The standard curve was plotted or regression equation was established density as the y-axis. Three portions of synovial fluids $(1 \mathrm{ml})$ were weighed and put into 3 numbered test tubes. Afterwards, $9 \mathrm{ml}$ mixture of Potassium Nitrate $\left(\mathrm{KNO}_{3}\right)$, isopropyl alcohol and phosphate buffer was added into each test tube, and $1.0 \mathrm{ml}$ of trichloroacetic acid mixed as a control. Then all the tubes were connected to a vacuum pump in a vacuum dryer for air exhaust, and kept in dark at below $30^{\circ}$ for $30 \mathrm{~min}$ for thermal insulation. Subsequently, $1.0 \mathrm{ml}$ of trichloroacetic acid was added into the tubes and shaken well. After 2 min, $2 \mathrm{ml}$ of the supernatant was collected and added as a reference. According to the standard curve, the enzymatic activity was calculated.

Sampling of cartilage tissues, Hematoxylin and Eosin (HE) staining and immunohistochemical assay: 
and quantified with high-resolution pathological image analysis system (HPIAS-1000). The percentage (\%) of positive area to total one in the entire tissue was calculated under a light microscope. Five visual fields were randomly selected for each section, and the results were averaged.

\section{Statistical analysis:}

All data were analyzed by Statistical Package for the Social Sciences (SPSS) 13.0 software and plotted by Excel 2003 software. The categorical data were expressed as $\mathrm{X} \pm \mathrm{s}$. Multigroup comparisons were performed by one-way analysis of variance, intergroup comparisons were conducted by the Student-NewmanKeuls (SNK) method, and intragroup comparisons were carried out by the $t$ test. $p<0.05$ was considered statistically significant.

\section{RESULTS AND DISCUSSION}

In Group A, the HE staining was even without destaining. The articular cartilage surface was smooth and flat with uniformly distributed chondrocytes. In Group B, the HE staining was less even with obvious destaining. The articular cartilage surface became thinner with fractures deep in the subchondral bone. The chondrocytes were arranged disorderedly, and the tide line vanished. With increasing concentration of L-NMMA, the damage in articular cartilage tissue was significantly alleviated (fig. 2). There were significant differences in the Mankin scores between groups $(\mathrm{F}=133.873, \mathrm{p}<0.01)$ (Table 1). The Mankin scores of Group B-E were significantly higher than that of Group A. Starting from Group B, the Mankin score significantly declined with increasing dose of L-NMMA (p<0.05) (fig. 3).

The expression levels of NO in the synovial fluid of Group B was $(90.55 \pm 15.72) \mathrm{pg} / \mathrm{ml}$ which was significantly higher than that of Group A [ $(15.33 \pm 3.21)$ $\mathrm{pg} / \mathrm{ml}](\mathrm{p}<0.01)$. With increasing concentration of L-NMMA, the expression level of NO in synovial fluid significantly decreased $(\mathrm{p}<0.05)$ (Table 2 and fig. 4$)$.

Before treatment, the expression levels of serum NO in all groups were similar ( $p>0.05)$. After treatment, the expression level of serum NO was $(21.54 \pm 2.16)$ $\mathrm{pg} / \mathrm{ml}$ in Group B, which was significantly higher than that of Group A [(14.98 \pm 2.16$) \mathrm{pg} / \mathrm{ml}](\mathrm{p}<0.01)$. With increasing concentration of L-NMMA, the expression level of serum NO significantly decreased $(\mathrm{p}<0.05)$ (Table 3).

The chondrocyte AI values of all groups were similar before treatment ( $>0.05)$. After treatment, AI of Group B was (25.15 \pm 7.72$)$ which was significantly higher than that of Group A $[(2.73 \pm 1.69)](\mathrm{p}<0.01)$. With rising concentration of L-NMMA, the apoptosis rate and AI dropped significantly $(\mathrm{p}<0.05)$ (Table 4$)$.

In Group B, the expression level of Bax in articular cartilage was significantly higher than that of Group A $(p<0.01)$. With elevating concentration of L-NMMA, the Bax expression level significantly reduced $(\mathrm{p}<0.05)$. The expression level of Bcl-2 was not significantly different from that of Group A ( $>0.05)$. However, with increasing concentration of L-NMMA, both Bcl-

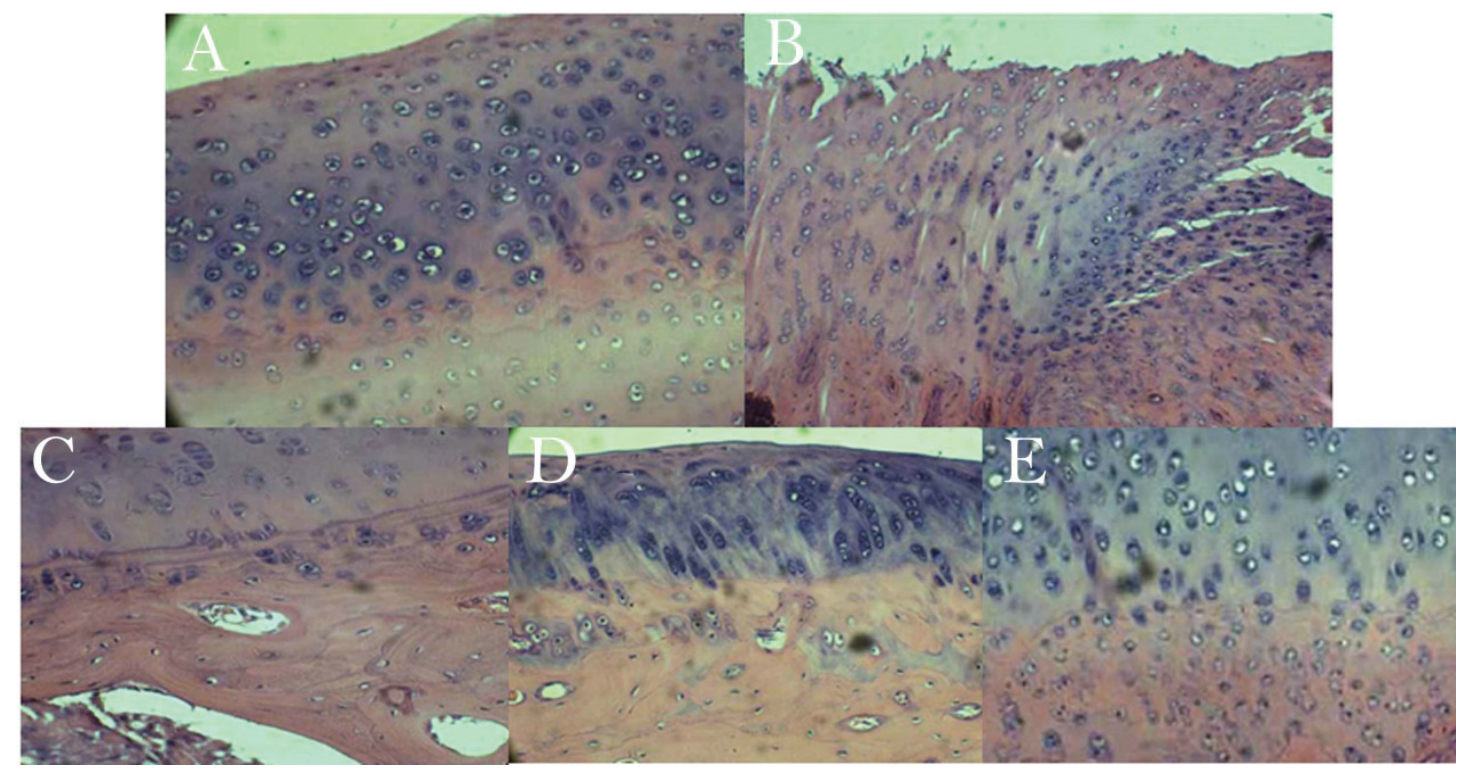

Fig. 2: HE staining results of articular cartilages (magnification: 200x)

A-E: Normal group, model group, low-dose L-NMMA treatment group, medium-dose L-NMMA treatment group and high-dose L-NMMA treatment group 
TABLE 1: MANKIN SCORES OF ARTICULAR CARTILAGE (x士s)

\begin{tabular}{llccc}
\hline Group & $\mathrm{n}$ & Mankin score & $\mathrm{F}$ & $\mathrm{P}$ \\
\hline A & 6 & $0.00 \pm 0.00$ & & \\
B & 6 & $12.73 \pm 1.22^{\mathrm{a}}$ & & \\
C & 6 & $10.38 \pm 0.97^{\mathrm{a}}$ & 161.21 & $<0.01$ \\
D & 6 & $8.96 \pm 0.79^{\mathrm{ab}}$ & & \\
E & 6 & $5.71 \pm 0.55^{\mathrm{abcd}}$ & &
\end{tabular}

aCompared with Group A, $p<0.05$; ${ }^{\text {b}}$ compared with Group B, $p<0.05$; compared with Group C, $p<0.05$; ${ }^{\mathrm{d}}$ compared with Group D, $p<0.05$

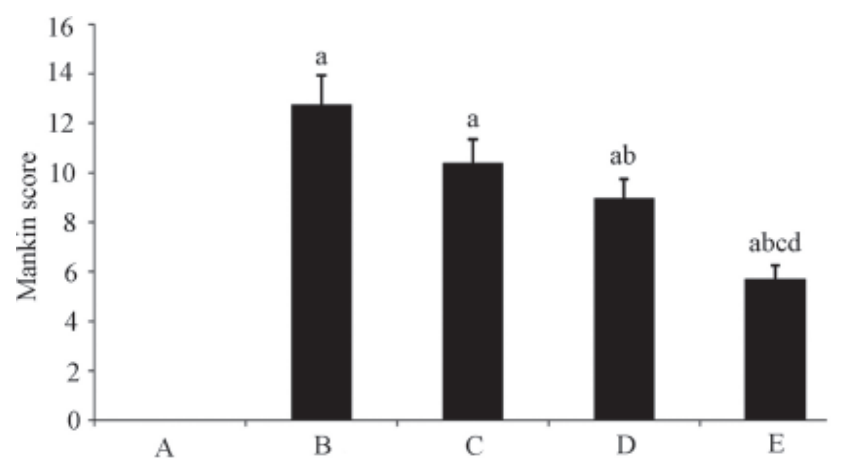

Fig. 3: Mankin scores

A-E: Normal group, model group, low-dose L-NMMA treatment group, medium-dose L-NMMA treatment group and highdose L-NMMA treatment group. a: Compared with Group A, p $<0.05$; b: compared with Group $B, p<0.05$; c: compared with Group C, p $<0.05$; d: compared with Group D, p $<0.05$

\section{TABLE 2: NO LEVELS IN JOINT FLUIDS ( $x \pm s$ )}

\begin{tabular}{llccc}
\hline Group & $\mathrm{n}$ & NO content $(\mathrm{pg} / \mathrm{ml})$ & $\mathrm{F}$ & $\mathrm{P}$ \\
\hline A & 6 & $15.33 \pm 3.21$ & & \\
B & 6 & $90.55 \pm 15.72^{\mathrm{a}}$ & & \\
C & 6 & $66.87 \pm 11.13^{\mathrm{ab}}$ & 412.451 & $<0.01$ \\
D & 6 & $42.71 \pm 7.54^{\mathrm{abc}}$ & & \\
E & 6 & $27.56 \pm 5.91^{\mathrm{abc}}$ & & \\
\hline
\end{tabular}

a Compared with Group A, $p<0.05$; ${ }^{\text {}}$ compared with Group B, $p<0.05$; ${ }^{c}$ Compared with Group C, $p<0.05$

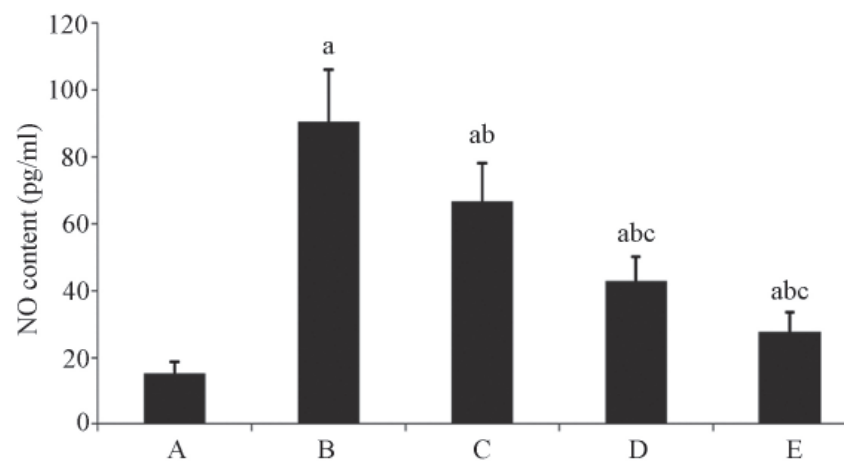

Fig. 4: NO contents

A-E: Normal group, model group, low-dose L-NMMA treatment group, medium-dose L-NMMA treatment group and highdose L-NMMA treatment group. a: Compared with Group A, $\mathbf{p}<0.05$; b: compared with Group B, $\mathbf{p}<0.05$; c: compared with Group C, $\mathbf{p}<0.05$

2 expression and $\mathrm{Bcl}-2 / \mathrm{Bax}$ ratio were significantly elevated $(\mathrm{p}<0.05)$ (Table 5, fig. 5-8).
NO, which is a small molecule widely existing in the physiological and pathophysiological media of human body, also has a simple structure in the form of free radicals. This molecule is readily soluble in lipids and can easily spread to the internal and external cellular environments through the cell membrane barrier. Therefore, it has a wide variety of biological functions, playing crucial roles in the onset and progression of $\mathrm{OA}^{[9,10]}$. NO in joint is mainly derived from the cells and chondrocytes of joint synovium. The secretion of inflammatory cytokines can significantly simulate articular chondrocytes and synovial cells, so the expression level of iNOS is gradually elevated, promoting the production of $\mathrm{NO}$ molecules in joints ${ }^{[11,12]}$. In addition, inflammatory cytokines and lipopolysaccharides in vivo can significantly stimulate the secretion of NO molecules in human body ${ }^{[13,14]}$. In the case of $\mathrm{OA}$, the interactions between these factors

\section{TABLE 3: NO LEVELS IN SERUM ( $\mathrm{x} \pm \mathrm{s}, \mathrm{pg} / \mathrm{ml})$}

\begin{tabular}{lccccc}
\hline Group & $\mathrm{n}$ & Before & After & $\mathrm{t}$ & $\mathrm{p}$ \\
\hline $\mathrm{A}$ & 6 & $13.38 \pm 1.98$ & $14.98 \pm 2.16$ & 0.447 & 0.665 \\
$\mathrm{~B}$ & 6 & $13.19 \pm 2.12$ & $21.54 \pm 2.16^{\mathrm{a}}$ & 6.596 & $<0.01$ \\
$\mathrm{C}$ & 6 & $12.91 \pm 2.21$ & $19.88 \pm 2.15^{\mathrm{a}}$ & 5.914 & $<0.01$ \\
$\mathrm{D}$ & 6 & $12.91 \pm 2.32$ & $15.99 \pm 2.01^{\mathrm{b}}$ & 2.542 & 0.029 \\
$\mathrm{E}$ & 6 & $12.97 \pm 2.13$ & $14.889 \pm 1.95^{\mathrm{abc}}$ & 1.507 & 0.163 \\
$\mathrm{~F}$ & - & 0.031 & 15.251 & & \\
p & - & 0.998 & $<0.01$ & & \\
\hline \multicolumn{7}{c}{ Compared with Group A, $\mathrm{p}<0.05 ;{ }^{\mathrm{b}}$ Compared with Group B, $\mathrm{p}<0.05 ;$}
\end{tabular}
compared with Group C, $\mathrm{p}<0.05$

TABLE4:APOPTOTIC INDICES OF CHONDROCYTES (X士s)

\begin{tabular}{lccccc}
\hline Group & $\mathrm{n}$ & Before & After & $\mathrm{t}$ & $\mathrm{p}$ \\
\hline A & 6 & $3.75 \pm 1.01$ & $3.84 \pm 0.99$ & 0.091 & 0.929 \\
$\mathrm{~B}$ & 6 & $3.81 \pm 1.12$ & $28.21 \pm 6.12^{\mathrm{a}}$ & 7.818 & $<0.01$ \\
C & 6 & $3.84 \pm 0.96$ & $21.98 \pm 5.84^{\mathrm{ab}}$ & 6.982 & $<0.01$ \\
D & 6 & $3.78 \pm 0.99$ & $13.76 \pm 3.17^{\mathrm{abc}}$ & 5.204 & $<0.01$ \\
E & 6 & $3.77 \pm 1.01$ & $8.55 \pm 2.21^{\mathrm{bc}}$ & 3.093 & 0.011 \\
F & - & 0.010 & 21.413 & & \\
p & - & 1.000 & $<0.01$ & & \\
\hline a Compared with Group A, $\mathrm{p}<0.05 ;{ }^{\mathrm{b}}$ Compared with Group B, $\mathrm{P}<0.05 ;$
\end{tabular}
compared with Group C, $\mathrm{p}<0.05$

TABLE 5: EXPRESSIONS OF BAX AND BCL-2 AND BCL-2/BAX RATIOS

\begin{tabular}{lcccc}
\hline Group & $\mathrm{n}$ & $\mathrm{Bcl}-2$ & $\mathrm{Bax}$ & $\mathrm{Bcl}-2 / \mathrm{Bax}$ \\
\hline A & 6 & $4.59 \pm 1.48$ & $5.97 \pm 1.58$ & $0.77 \pm 0.19$ \\
B & 6 & $4.86 \pm 1.53$ & $22.79 \pm 5.87^{\mathrm{a}}$ & $0.21 \pm 0.08^{\mathrm{a}}$ \\
C & 6 & $7.97 \pm 3.39$ & $18.95 \pm 5.22^{\mathrm{a}}$ & $0.42 \pm 0.25$ \\
D & 6 & $11.47 \pm 3.83^{\mathrm{ab}}$ & $14.68 \pm 3.19^{\mathrm{ab}}$ & $078 \pm 0.29^{\mathrm{bc}}$ \\
E & 6 & $14.78 \pm 4.65^{\mathrm{bc}}$ & $12.24 \pm 2.69^{\mathrm{bc}}$ & $1.21 \pm 0.22^{\mathrm{abcd}}$ \\
F & - & 11.774 & 16.176 & 15.549 \\
P & - & 0.000 & 0.000 & 0.000 \\
\hline
\end{tabular}

aCompared with Group A, $p<0.05$; ${ }^{b}$ compared with Group B, $p<0.05$; compared with Group C, $p<0.05$; ${ }^{\mathrm{d}}$ compared with Group D, $\mathrm{p}<0.05$ 


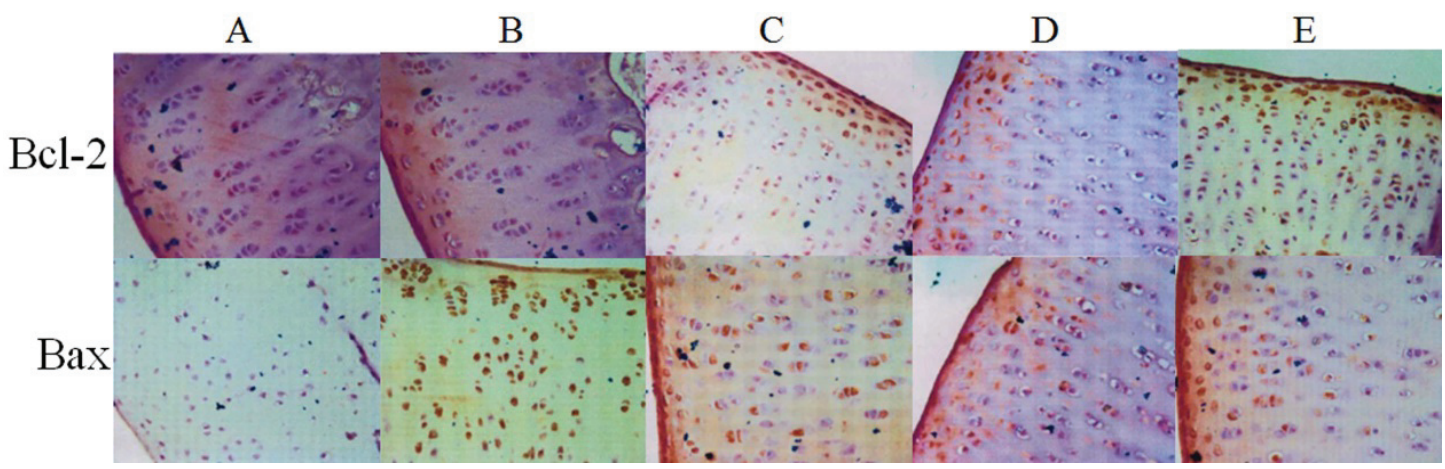

Fig. 5: Expressions of Bcl-2 and Bax (magnification: 400x)

A-E: Normal group, model group, low-dose L-NMMA treatment group, medium-dose L-NMMA treatment group and high-dose L-NMMA treatment group

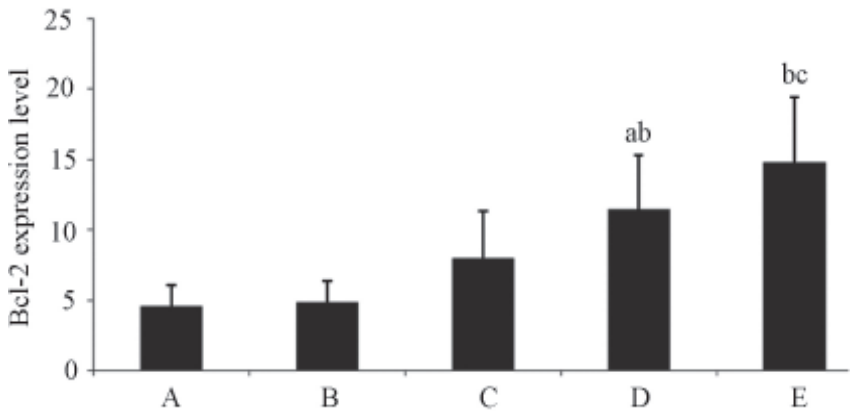

Fig. 6: Bcl-2 expressions

A-E: Normal group, model group, low-dose L-NMMA treatment group, medium-dose L-NMMA treatment group and highdose L-NMMA treatment group. a: Compared with Group A, p $<0.05$; b: compared with Group $B, p<0.05$; c: compared with Group C, p $<0.05$

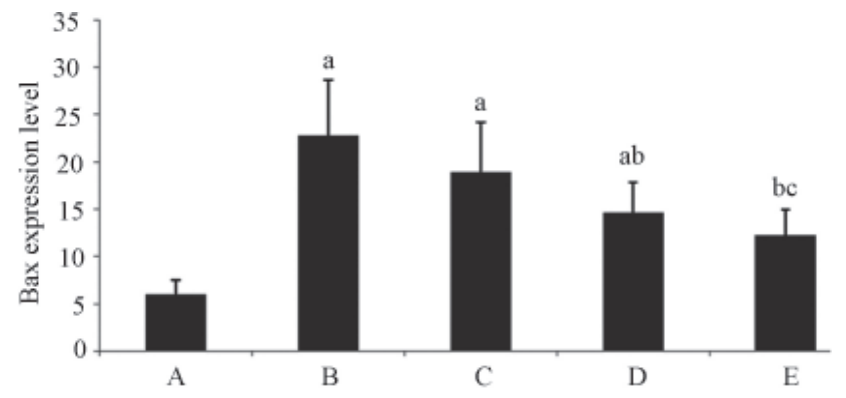

Fig. 7: Bax expressions

A-E: Normal group, model group, low-dose L-NMMA treatment group, medium-dose L-NMMA treatment group and highdose L-NMMA treatment group. a: Compared with Group A, p $<0.05$; b: compared with Group B, $\mathbf{p}<0.05$; c: compared with Group C, p $<0.05$

gradually lead to aggravation. Accordingly, completely blocking this vicious cycle can drastically relieve damage to the articular cartilage, finally significantly alleviating OA.

NOS's consist of neuron NOS (nNOS), iNOS and endothelial NOS (eNOS), among which iNOS is expressed in the articular chondrocytes of human, rabbit and sheep. OA pathological changes can be induced by injecting collagenase into the articular cavity of normal mice and those with iNOS gene deficiency ${ }^{[15]}$, and the latter mice were less prone to these changes. $\mathrm{NO}$ and its

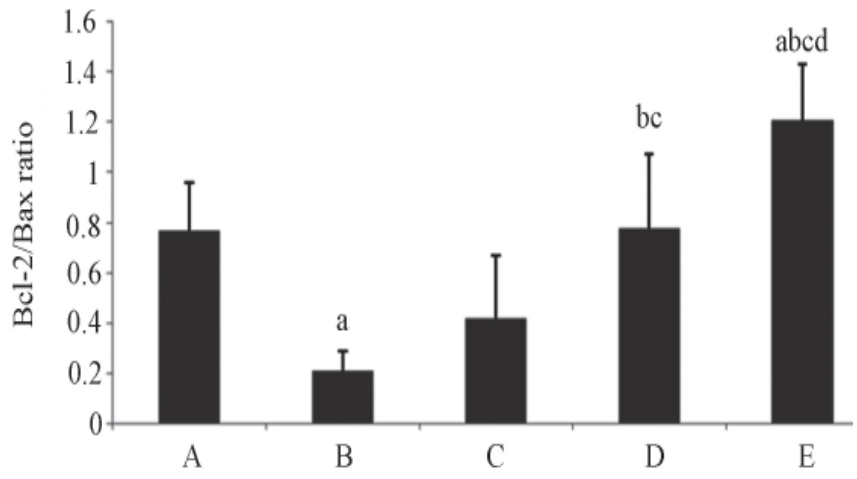

Fig. 8: Bcl-2/Bax ratios

A-E: Normal group, model group, low-dose L-NMMA treatment group, medium-dose L-NMMA treatment group and highdose L-NMMA treatment group. a: Compared with Group A, p $<0.05$; b: compared with Group B, $\mathbf{p}<0.05$; c: compared with Group C, p<0.05; d: compared with Group D, p $<0.05$

byproducts may stimulate and induce the apoptosis of articular chondrocytes, thus inhibiting the synthesis and facilitating the decomposition of substances such as protein polysaccharides and collagen ${ }^{[16]}$. As the protein polysaccharide content plummets in joint, the water content of articular chondrocytes also reduces markedly, finally inducing abnormal drying of articular cartilage which gradually loses its original gloss ${ }^{[17,18]}$. The obvious decline in collagen content may significantly reduce the elasticity of articular cartilage, so it lacks the normal stress and easily wears during movement, leading to apparent fracture ${ }^{[19]}$. Afterwards, immune reactions occur, which generate more inflammatory mediators such as IL- $1 \beta$ and TNF- $\alpha$, activate iNOS in articular chondrocytes and finally produce numerous NO substances.

Bcl-2 gene, as a proto-oncogene located in the short arm of chromosome 18 of human beings, can be found in the breakpoints of lymphoma cells. It is capable of inhibiting cell apoptosis and prolonging the survival time $^{[20]}$. Bax gene, which is mainly located in the chromosome 11 of human beings, is one of the most 
important genes in the Bcl-2 family that promotes cell $\operatorname{apoptosis}^{[21,22]}$.

The overexpression of Bcl-2 gene in vivo can evidently inhibit cell apoptosis mediated by Fas gene. This gene is expressed in the articular cartilage of OA patients ${ }^{[23]}$. Bcl-2 messenger ribonucleic acid (mRNA) is highly expressed in articular chondrocytes close to the articular cartilage defect areas of OA patients. Moreover, the apparent increase of Bax mRNA in the articular chondrocytes of OA patients is one of the important factors for articular chondrocyte apoptosis, and the obvious up-regulation of Bcl-2 mRNA expression suggests that articular chondrocytes are protected from damage and apoptosis.

In summary, L-NMMA can significantly reduce the expression levels of NO in synovial fluid and serum, and may inhibit the apoptosis of articular chondrocytes by raising $\mathrm{Bcl}-2 / \mathrm{Bax}$ ratio. Therefore, L-NMMA is feasibly applicable to the clinical treatment of OA.

\section{Acknowledgements:}

None

\section{Conflict of interests:}

The authors declared no conflict of interest.

\section{REFERENCES}

1. Hochberg MC. Osteoarthritis year 2012 in review: clinical. Osteoarthritis Cartilage 2012;20(12):1465-9.

2. Suri P, Morgenroth DC, Hunter DJ. Epidemiology of osteoarthritis and associated comorbidities. Phys Med Rehabil 2012;4:S10-9.

3. Chen Q, Zhang B, Yi T, Xia C. Increased apoptosis in human knee osteoarthritis cartilage related to the expression of protein kinase $\mathrm{B}$ and protein kinase $\mathrm{C} \alpha$ in chondrocytes. Folia Histochem Cytobiol 2012;50(1):137-43.

4. Zhao Z, Ji H, Jing R, Liu C, Wang M, Zhai L, et al. Extracorporeal shock-wave therapy reduces progression of knee osteoarthritis in rabbits by reducing nitric oxide level and chondrocyte apoptosis. Arch Orthop Trauma Surg 2012;132(11):1547-53.

5. Zhou Y, Liu SQ, Yu L, He B, Wu SH, Zhao Q, et al. Berberine prevents nitric oxide-induced rat chondrocyte apoptosis and cartilage degeneration in a rat osteoarthritis model via AMPK and p38 MAPK signaling. Apoptosis 2015;20(9):1187-99.

6. Ide K, Worthley M, Anderson T, Poulin MJ. Effect of systemic administration of the nitric oxide synthase inhibitor L-NMMA on the human ventilatory response to hypoxia. Adv Exp Med Biol 2008;605:41-5.

7. Yoshimi T, Kikuchi T, Obara T, Yamaguchi T, Sakakibara Y, et al. Effects of high-molecular-weight sodium hyaluronate on experimental osteoarthrosis induced by the resection of rabbit anterior cruciate ligament. Clin Orthop Relat Res 1994;298:296-304.

8. Neo H, Ishimaru JI, Kurita K, Goss AN. The effect of hyaluronic acid on experimental temporomandibular joint osteoarthrosis in the sheep. J Oral Maxillofac Surg 1997;55(10):1114-9.

9. Tao R, Wang S, Xia X, Wang Y, Cao Y, Huang Y, et al. Pyrroloquinoline quinone slows down the progression of osteoarthritis by inhibiting nitric oxide production and metalloproteinase synthesis. Inflammation 2015;38(4):154655.

10. Jin P, Wiraja C, Zhao J, Zhang J, Zheng L, Xu C. Nitric oxide nanosensors for predicting the development of osteoarthritis in rat model. ACS Appl Mater Interfaces 2017;9(30):25128-37.

11. Santoro A, Conde J, Scotece M, Abella V, Lopez V, Pino J, et al. Choosing the right chondrocyte cell line: Focus on nitric oxide. J Orthop Res 2015;33(12):1784-8.

12. Wang G, Yan Q, Woods A, Aubrey LA, Feng Q, Beier F. Inducible nitric oxide synthase-nitric oxide signaling mediates the mitogenic activity of Rac1 during endochondral bone growth. J Cell Sci 2011;124(20):3405-13.

13. Chung HS, Kim H, Bae H. Phenelzine (monoamine oxidase inhibitor) increases production of nitric oxide and proinflammatory cytokines via the $\mathrm{NF}-\kappa \mathrm{B}$ pathway in lipopolysaccharide-activated microglia cells. Neurochem Res 2012;37(10):2117-24.

14. Lee TH, Jung M, Bang MH, Chung DK, Kim J. Inhibitory effects of a spinasterol glycoside on lipopolysaccharideinduced production of nitric oxide and proinflammatory cytokines via down-regulating MAP kinase pathways and $\mathrm{NF}-\kappa \mathrm{B}$ activation in RAW264. 7 macrophage cells. Int Immunopharmacol 2012;13(3):264-70.

15. Van den Berg WB, Van de Loo F, Arntz OJ. Animal models of arthritis in NOS2-deficient mice. Osteoarthritis Cartilage 1999;7(4):413-5.

16. de Andres MC, Maneiro E, Martin MA, Arenas J, Blanco FJ. Nitric oxide compounds have different effects profiles on human articular chondrocyte metabolism. Arthritis Res Ther 2013;15(5):1-2.

17. Chen Q, Mei X, Han G, Ling P, Guo B, Guo Y, et al. Xanthan gum protects rabbit articular chondrocytes against sodium nitroprusside-induced apoptosis in vitro. Carbohydr Polym 2015;131:363-9.

18. Zhang C, Yu L, Zhou Y, Zhao Q, Liu SQ. Chitosan oligosaccharides inhibit IL-1 $\beta$-induced chondrocyte apoptosis via the P38 MAPK signaling pathway. Glycoconj J 2016;33(5):735-44.

19. Genemaras AA, Reiner T, Huang CY, Kaplan L. Early intervention with interleukin-1 receptor antagonist protein modulates catabolic microRNA and mRNA expression in cartilage after impact injury. Osteoarthritis Cartilage 2015;23(11):2036-44.

20. Humlova Z. Protooncogene bcl-2 in process of apoptosis. Review article. Sb Lek 2002;103(4):419-25.

21. Didonna A, Sussman J, Benetti F, Legname G. The role of Bax and caspase-3 in doppel-induced apoptosis of cerebellar granule cells. Prion 2012;6(3):309-16.

22. Wakeman D, Guo J, Santos JA, Wandu WS, Schneider JE, McMellen ME, et al. p38 MAPK regulates Bax activity and apoptosis in enterocytes at baseline and after intestinal resection. Am J Physiol Gastrointest Liver Physiol 2012;302(9):G9971005.

23. Mobasheri A, Matta C, Zakany R, Musumeci G. Chondrosenescence: definition, hallmarks and potential role in the pathogenesis of osteoarthritis. Maturitas 2015;80(3):23744. 